\title{
Effect of selective lymph node dissection based on patterns of lobe-specific lymph node metastases on patient outcome in patients with resectable non-small cell lung cancer: A large-scale retrospective cohort study applying a propensity score
}

\author{
Futoshi Ishiguro, MD, ${ }^{\mathrm{a}}$ Keitaro Matsuo, MD, ${ }^{\mathrm{b}}$ Takayuki Fukui, MD, ${ }^{\mathrm{a}}$ Shoichi Mori, MD, ${ }^{\mathrm{a}, \mathrm{c}}$ \\ Shunzo Hatooka, MD, ${ }^{a}$ and Tetsuya Mitsudomi, MD $^{\mathrm{a}}$
}

\begin{abstract}
Objective: Lobectomy with systematic complete mediastinal lymph node dissection is standard surgical treatment for localized non-small cell lung cancer. However, selective mediastinal lymph node dissection based on lobe-specific metastases (selective dissection) has often been performed. This study was designed to evaluate the validity of the selective lymph node dissection.
\end{abstract}

\begin{abstract}
Methods: From 1995 through 2003, 625 patients in our hospital had surgery for complete mediastinal lymph node dissection and 147 for selective dissection. We evaluated whether selective dissection adversely affected overall survival. To minimize possible biases due to confounding by treatment indication, we performed a retrospective cohort analysis by applying a propensity score. The propensity score was calculated by logistic regression based on 15 factors available that were potentially associated with treatment indication. Patients were divided into 4 groups according to quartile, and comparison between selective dissection and complete mediastinal lymph node dissection was made using propensity score quartile-stratified Cox proportional hazard models.
\end{abstract}

\begin{abstract}
Results: Comparison of baseline characteristics between patients having selective dissection and patients having complete mediastinal lymph node dissection according to propensity score quartile supported comparability of the 2 groups. The 5 -year overall survival rates were $76.0 \%$ for selective dissection versus $71.9 \%$ for complete mediastinal lymph node dissection. The 5-year survival probabilities stratified by propensity score quartile consistently showed no marked difference. In multivariate models, there was no significant difference between the 2 groups (hazard ratio $=1.17, P=.500$ ) as also seen in the analysis without propensity score (hazard ratio $=1.06$; $95 \%$ confidence interval, $0.68-1.64 ; P=.810$ ). Therefore, selective dissection showed no significant impact on poor survival compared with complete mediastinal lymph node dissection.
\end{abstract}

Conclusions: Selective lymph node dissection did not worsen the survival of patients with non-small cell lung cancer. (J Thorac Cardiovasc Surg 2010;139:1001-6)

The standard surgical treatment for patients with localized non-small cell lung cancer (NSCLC) is lobectomy or pneumonectomy with complete systematic mediastinal as well as hilar lymphadenectomy, known as radical complete lymph node dissection (CD). ${ }^{1,2}$ However, the significance of lymphadenectomy is controversial. Some authors advocate the benefit of lymphadenectomy on histologic staging of lymph node spread but found no influence on overall survival (OS) or disease-free survival. ${ }^{3,4}$ Dissection of lymph nodes with-

\footnotetext{
From the Department of Thoracic Surgery, ${ }^{a}$ Aichi Cancer Center Hospital; Division of Epidemiology and Prevention, ${ }^{\mathrm{b}}$ Aichi Cancer Center Research Institute; and Department of Thoracic Surgery, ${ }^{\mathrm{c}}$ Japanese Red Cross Nagoya First Hospital, Nagoya, Japan.

Disclosures: None.

Received for publication Feb 18, 2009; revisions received May 20, 2009; accepted for publication July 8, 2009; available ahead of print Sept 7, 2009.

Address for reprints: Futoshi Ishiguro, MD, Department of Thoracic Surgery, Aichi Cancer Center Hospital, 1-1 Kanokoden, Chikusa-Ku Nagoya 461-8681, Japan (E-mail: hishi@aichi-cc.jp).

0022-5223/\$36.00

Copyright (c) 2010 by The American Association for Thoracic Surgery

doi:10.1016/j.jtcvs.2009.07.024
}

out cancer cells is considered to be futile and can potentially increase perioperative complications or may require longer operative times..$^{3-7}$ In contrast, others claim that lymphadenectomy is important for therapeutic purposes as well as for staging. ${ }^{8-11}$ Despite this controversy, there have been only 2 randomized controlled trials (RCTs) comparing $\mathrm{CD}$ with mediastinal lymph node sampling. ${ }^{4,9}$ Izbicki and colleagues ${ }^{4}$ concluded that there was no difference between the 2 groups in terms of both disease-free survival and OS. On the other hand, $\mathrm{Wu}$ and associates ${ }^{9}$ reported that $\mathrm{CD}$ has a prognostic impact on survival. However, these results are not conclusive because of limited sample size and lack of intention-to-treat analysis. In this regard, we have to wait for the results of an ongoing randomized trial (ACOSOG Z0030) in North America. ${ }^{12}$

It is clear that the location of primary tumor in the lobes influences mode and extent of nodal spread. ${ }^{13-15}$ For example, Okada and colleagues ${ }^{13}$ reported that among patients with skip N2 metastases (no N1 nodes involved) with an upper-lobe lesion, none had positive subcarinal nodes. Only 1 of 13 patients with lower-lobe lesions $(7.7 \%)$ showed nodal 


$$
\begin{aligned}
& \text { Abbreviations and Acronyms } \\
& \begin{aligned}
\text { CD } & =\text { complete lymph node dissection } \\
\text { NSCLC } & =\text { non-small cell lung cancer } \\
\text { OS } & =\text { overall survival } \\
\text { PS } & =\text { propensity score } \\
\text { RCT } & =\text { randomized controlled trial } \\
\text { SD } & =\text { selective dissection }
\end{aligned}
\end{aligned}
$$

spread to the upper mediastinum. Okada and colleagues ${ }^{13}$ suggested that lower mediastinal lymphadenectomy was dispensable if hilar and upper mediastinal nodes were tumor-free in upper-lobe tumors. For lower-lobe tumors, upper mediastinal lymphadenectomy was dispensable when the hilar and subcarinal nodes were tumor-free. These studies suggest validity of selective lymphadenectomy based on patterns of lobe-specific lymph node metastases.

From the above-mentioned data, selective dissection (SD) has often been performed for patients with no apparent lymph node metastasis or with poor pulmonary reserve, or for elderly patients, although there were no predefined criteria for type of lymphadenectomy. It should be noted, however, that SD is different from lymph node sampling mentioned above, in that lymph nodes that should be removed according to patterns of lymph node metastases are radically dissected.

There is currently no evidence from RCTs regarding the validity of SD compared with $\mathrm{CD}$. Large RCTs would take a long time and have great cost and therefore cannot be easily performed. The second best evidence should exist in a retrospective study comparing the 2 approaches. However, a serious concern with a retrospective analysis is that results might be biased by confounding for patient selection,,${ }^{5,6,10}$ because patients with earlier diseases, those with poor pulmonary reserve, or elderly patients are likely to receive SD.

To eliminate these biases as much as possible, we conducted a retrospective cohort analysis using a propensity score (PS) to evaluate validity of SD compared with CD. A PS is defined as the conditional probability of exposure to a treatment given preoperatively observed covariates. Hypothetically, patients with the same PS have the same probability of receiving SD or $\mathrm{CD}$. Therefore, patients receiving $\mathrm{SD}$ and patients receiving $\mathrm{CD}$ with the same $\mathrm{PS}$ provide similar comparability. Hence, results obtained by a retrospective study using a PS are assumed almost similar to those obtained by prospective RCT. ${ }^{16}$

\section{PATIENTS AND METHODS \\ Patients}

Approval for this study was obtained from and the need for individual patient consent was waived by the institutional review board. From 1995 through 2003, 893 patients with NSCLC had pulmonary resection at the Department of Thoracic Surgery, Aichi Cancer Center Hospital. Of them, 772 patients had potentially curative lobectomy, bilobectomy, or pneumonectomy, excluding 121 patients who had lesser resection (partial resection, segmentectomy, lobectomy without mediastinal node dissection, as shown in Figure 1). Patients who had neoadjuvant or adjuvant treatment were also excluded from this study.

\section{Surgical Technique}

Surgical techniques for resection of affected lobes were the same in both groups, consisting either of lobectomy, bilobectomy, or pneumonectomy. Tumors that exhibited adherence to neighboring structures were treated by extended resections with en bloc removal of the lobe or lung with adjacent organs. Locations of lymph nodes were described according to the lymph node map for lung cancer described by Naruke and associates. ${ }^{17}$

In the $\mathrm{CD}$ group, resection was combined with a radical systematic en bloc mediastinal lymphadenectomy as described by Naruke and colleauges ${ }^{1}$ and Martini and coworkers. ${ }^{2}$

In the SD group, lymph node dissection was performed based on patterns of lobe-specific lymph node metastases. When the tumor was located in the right upper lobe, the upper mediastinal lymph nodes (superior mediastinal nodes, paratracheal nodes, pretracheal nodes, and tracheobronchial nodes) were systematically removed. When the tumor was located in the left upper lobe, aortopulmonary window nodes and aortic nodes in addition to tracheobronchial nodes were resected. In these cases, dissection of lower mediastinum was not performed when the nodes in both the hilum and the upper mediastinum or aortic nodes were free from metastases as shown by intraoperative diagnosis. Intraoperative frozen section analyses were performed when lymph node metastases were suspected macroscopically, and when positive, all patients had CD. Alternatively, when the tumor was located in the lower lobe, subcarinal and lower mediastinal nodes were dissected, and dissection of the superior mediastinum was omitted when the intraoperative diagnosis was negative. By such definition, 625 patients belonged to the CD group and 147 to the SD group. All operations were performed via thoracotomy.

\section{Pre- and Postoperative Measurements}

Survival was determined by institutional database, which is updated with an annual institutional census or each patient visit. Serum carcinoembryonic antigen levels were measured using a chemiluminescent immunoassay kit (Abbott, Tokyo, Japan). Blood gas analyses were performed during rest in room air. Clinical and postsurgical staging was determined according to the TNM classification of the International Union Against Cancer. ${ }^{18}$ Spirometry testing was performed by medical technicians of the specialty using a spirometer. Trained medical staff asked about smoking history in detail,

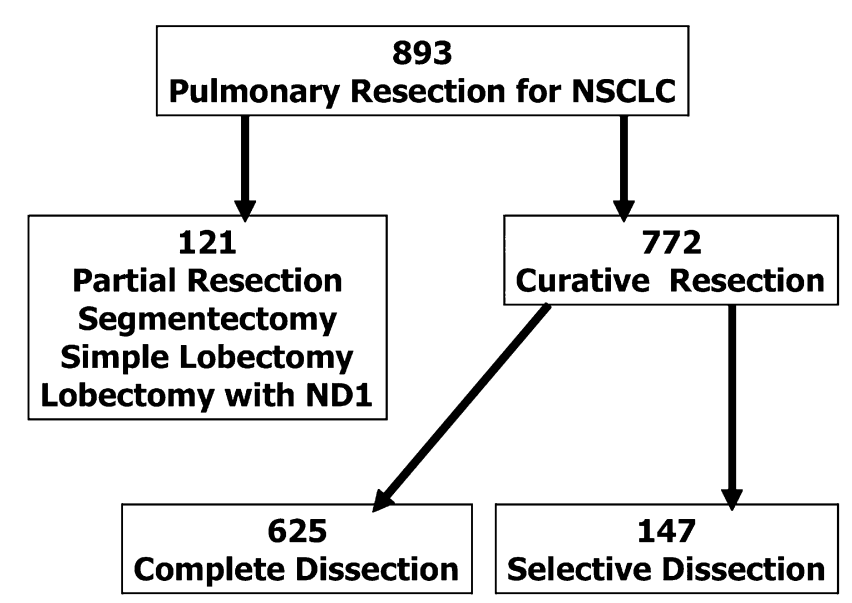

FIGURE 1. Presentation of the cohort and inclusion and exclusion criteria and the number of patients. NSCLC, Non-small cell lung cancer. 
TABLE 1. Covariates that are considered to concern selection of the types of lymph node dissection

\begin{tabular}{lc}
\hline \multicolumn{1}{c}{ Covariates } & Category \\
\hline Age at diagnosis (y) & $<40,40-59,60-69$, and $\geq 70$ \\
$\mathrm{Sex}$ & Male vs female \\
$\mathrm{CEA}$ at diagnosis & Continuous value \\
Arterial blood gas & \\
$\mathrm{PaO}_{2}, \mathrm{PaCO}_{2}$ & Continuous value \\
Pulmonary function & \\
$\%$ VC, \% FEV1.0, \% DLCO, & Continuous value \\
and FEV1.0 & \\
Clinical stage & \\
T factor, N factor & Ordinal variable \\
Smoking index & Continuous value \\
Histologic type & Adeno, squamous, and others \\
Operator & Surgeon 1, 2, 3, and 4 \\
Operative procedures & Lobectomy, extended lobectomy, \\
& bilobectomy, and pneumonectomy \\
\hline CEA, Carcinoembryonic antigen; $D L C O$, diffusing capacity for carbon monoxide; \\
FEV 1.0, forced expiratory volume in 1 second; $V C$, vital capacity.
\end{tabular}

and the Brinkman index, defined by the cigarettes smoked per day $\times$ total years of smoking, was recorded. Resected specimens were examined histopathologically, and histologic classification was performed according to the World Health Organization classification as shown in Table $1 .{ }^{19}$

\section{Statistical Methods}

Propensity score calculation. We calculated the PS using logistic regression based upon factors available that were thought to be potentially associated with patient selection, ${ }^{20}$ using the pscore command in STATA version 10 (STATA, College Station, Tex). ${ }^{21}$ Fifteen such factors included for calculation of the PS are summarized in Table 1. The number of blocks in the PS calculation was set as 5. After the calculation of their PS, subjects were divided into 4 groups according to quartile.

Survival analysis. Our primary end point was OS, which was defined as the interval between the date of operation and final date of observation or date of death. Comparison of the CD and SD groups was conducted using a log-rank test and a Cox proportional hazard model coupled with forward stepwise covariate selection (threshold $P$ values for removal and inclusion were .20 and .10, respectively) with stratification by PS quartile. The latter aimed to remove residual confounding after PS stratification. Factors examined in the stepwise Cox proportional hazard model were the 15 factors used to calculate PS (Table 1). Comparison of baseline characteristics between $\mathrm{SD}$ and $\mathrm{CD}$ were examined by the Wilcoxon rank sum test for continuous variables and the Fisher exact test or chi-square test for categorical variables as appropriate. All survival analyses were conducted with STATA version $10 .^{21}$

A total of 772 subjects provided statistical power of more than $88 \%$ (1-sided $\alpha=.05$ ) and $80 \%$ (2-sided $\alpha=.05$ ) to detect a 0.3 difference in the hazard ratio of SD relative to $\mathrm{CD}$, when final failure probability was assumed to be $40 \%$.

\section{RESULTS}

Characteristics of subjects in the $\mathrm{CD}$ and $\mathrm{SD}$ groups are shown in Table 2. Younger patients, patients in earlier stages, patients with adenocarcinoma, and those who had lobectomy were more frequently observed in the SD group, as expected. Therefore, one may assume that direct comparison between SD and CD may be confounded by patients'
TABLE 2. Patient characteristics

\begin{tabular}{|c|c|c|c|}
\hline Variables & CD (\%) & SD (\%) & $P$ value \\
\hline All patients & 625 & 147 & \\
\hline \multicolumn{4}{|l|}{ Sex } \\
\hline Male & $390(62)$ & $84(57)$ & \multirow[t]{2}{*}{$.22 *$} \\
\hline Female & $235(38)$ & $63(43)$ & \\
\hline Age (y) & $\begin{array}{l}19-80 \\
(\text { median 62) }\end{array}$ & $\begin{array}{l}34-82 \\
(\text { median 69) }\end{array}$ & $.0001 \dagger$ \\
\hline \multicolumn{4}{|l|}{ Clinical stage } \\
\hline IA & $276(44)$ & $94(64)$ & \multirow[t]{6}{*}{$.0001^{*}$} \\
\hline IB & $182(29)$ & $46(31)$ & \\
\hline IIA & $7(1)$ & $0(0)$ & \\
\hline IIB & $73(12)$ & $6(4)$ & \\
\hline IIIA & $76(12)$ & $1(1)$ & \\
\hline IIIB & $11(2)$ & $0(0)$ & \\
\hline \multicolumn{4}{|l|}{ Histology } \\
\hline $\mathrm{AD}$ & $436(70)$ & $117(80)$ & \multirow[t]{3}{*}{$.02 *$} \\
\hline SQC & $128(20)$ & $16(11)$ & \\
\hline Others & $61(10)$ & $14(9)$ & \\
\hline \multicolumn{4}{|l|}{ Operation } \\
\hline Lobectomy & $522(84)$ & $140(95)$ & \multirow[t]{2}{*}{$.002^{*}$} \\
\hline $\begin{array}{l}\text { Bilobectomy/ } \\
\text { pneumonectomy/ } \\
\text { extended lobectomy }\end{array}$ & $66(11)$ & $6(4)$ & \\
\hline $\begin{array}{l}\text { Lobectomy with adjacent } \\
\text { organ resection }\end{array}$ & $37(5)$ & $1(1)$ & \\
\hline \multicolumn{4}{|l|}{ Operator } \\
\hline 1 & $189(30)$ & $51(35)$ & \multirow[t]{4}{*}{$.001 *$} \\
\hline 2 & $149(24)$ & $15(10)$ & \\
\hline 3 & $264(42)$ & $79(54)$ & \\
\hline 4 & $23(4)$ & $2(1)$ & \\
\hline
\end{tabular}

$C D$, Complete dissection; $S D$, selective dissection; $A D$, adenocarcinoma; $S Q C$, squamous cell carcinoma. *Fisher exact test or chi-square test. $\dagger$ Wilcoxon rank-sum test.

treatment indication based upon background characteristics. Table 3 shows a comparison of these characteristics between $\mathrm{CD}$ and SD according to PS quartile. The number of subjects in quartiles $1,2,3$, and 4 according to the mode of lymph node dissection (CD; SD) were (188; 5), (172; 21), (157; $36)$, and $(108 ; 85)$, respectively. This demonstrates equivalent distribution of background characteristics in each PS quartile between the 2 groups, except that age at operation was significantly higher in the SD group in the highest quartile group.

Figure 2 shows OS after surgery for the $\mathrm{CD}$ and SD groups. The 5-year survival probabilities were $71.9 \%$ (95\% confidence interval [CI]: 68.0-75.5) for the CD group and 76.0\% (95\% CI: 65.3-83.9) for the SD group. There was no significant difference in OS between the 2 groups $(P=.29)$ without stratification by PS. After consideration of PS, difference in survival between the 2 groups was decreased $(P=.8098)$. The 5-year survival probabilities stratified by PS quartile are shown in Table 4. This also indicates that the 5-year OSs are consistently comparable across each PS quartile.

In the Cox proportional hazard model not considering PS, a crude hazard ratio (HR) for $\mathrm{SD}$ relative to $\mathrm{CD}$ was 1.06 
TABLE 3. Patient characteristics stratified by PS quartile

\begin{tabular}{|c|c|c|c|c|c|c|c|c|c|c|c|c|}
\hline \multirow[b]{2}{*}{ Variables } & \multicolumn{3}{|c|}{ Quartile 1} & \multicolumn{3}{|c|}{ Quartile 2} & \multicolumn{3}{|c|}{ Quartile 3} & \multicolumn{3}{|c|}{ Quartile 4} \\
\hline & CD & SD & $P$ value & CD & SD & $P$ value & CD & SD & $P$ value & CD & SD & $P$ value \\
\hline No. of patients & 188 & 5 & & 172 & 21 & & 157 & 36 & & 108 & 85 & \\
\hline \multicolumn{13}{|l|}{ Sex } \\
\hline Male & 139 & 5 & $.186^{*}$ & 101 & 12 & $.890^{*}$ & 87 & 18 & $.556^{*}$ & 64 & 49 & $.821 *$ \\
\hline Female & 49 & 0 & & 71 & 9 & & 70 & 18 & & 44 & 36 & \\
\hline Age $(y)$, median & 58 & 59 & $.773 \dagger$ & 59 & 57 & $.446 \dagger$ & 63 & 61 & $.803 \dagger$ & 70 & 73 & $<.001 \dagger$ \\
\hline \multicolumn{13}{|l|}{ Clinical stage } \\
\hline IA & 23 & 1 & $.876^{*}$ & 83 & 10 & $.885^{*}$ & 95 & 26 & $.417 *$ & 75 & 57 & $.993^{*}$ \\
\hline IB & 33 & 1 & & 60 & 9 & & 57 & 9 & & 32 & 27 & \\
\hline IIA & 4 & 0 & & 3 & 0 & & 0 & 0 & & 0 & 0 & \\
\hline IIB & 42 & 2 & & 25 & 2 & & 5 & 1 & & 1 & 1 & \\
\hline IIIA & 76 & 1 & & 0 & 0 & & 0 & 0 & & 0 & 0 & \\
\hline IIIB & 10 & 0 & & 1 & 0 & & 0 & 0 & & 0 & 0 & \\
\hline \multicolumn{13}{|l|}{ Histology } \\
\hline $\mathrm{AD}$ & 92 & 4 & $.356^{*}$ & 125 & 17 & $.517 *$ & 128 & 17 & $.765^{*}$ & 91 & 66 & $.428^{*}$ \\
\hline SQC & 66 & 1 & & 34 & 2 & & 20 & 2 & & 8 & 8 & \\
\hline LA & 30 & 0 & & 13 & 2 & & 9 & 2 & & 9 & 11 & \\
\hline \multicolumn{13}{|l|}{ Operation } \\
\hline Lobectomy & 115 & 3 & $1.0^{*}$ & 149 & 20 & $.500^{*}$ & 152 & 35 & $.895 *$ & 106 & 82 & $.767 *$ \\
\hline $\begin{array}{l}\text { Bilobectomy/ } \\
\text { pneumonectomy/ } \\
\text { extended lobectomy }\end{array}$ & 42 & 1 & & 17 & 1 & & 5 & 1 & & 2 & 3 & \\
\hline $\begin{array}{l}\text { Lobectomy with } \\
\text { adjacent organ } \\
\text { resection }\end{array}$ & 31 & 1 & & 6 & 0 & & 0 & 0 & & 0 & 0 & \\
\hline \multicolumn{13}{|l|}{ Operator } \\
\hline 1 & 43 & 0 & $.528 *$ & 51 & 6 & $.987^{*}$ & 53 & 15 & $.832 *$ & 42 & 30 & $.447^{*}$ \\
\hline 2 & 64 & 2 & & 63 & 8 & & 22 & 4 & & 0 & 1 & \\
\hline 3 & 69 & 3 & & 51 & 6 & & 78 & 16 & & 66 & 54 & \\
\hline 4 & 12 & 0 & & 7 & 1 & & 4 & 1 & & 0 & 0 & \\
\hline
\end{tabular}

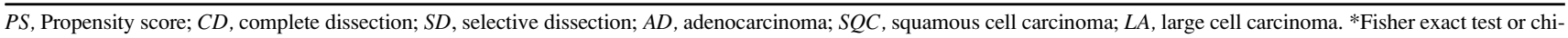
square test. †Wilcoxon rank-sum test.

(95\% confidence interval, $0.68-1.64 ; P=.810)$. Results of stepwise multivariate analyses adjusted by PS are shown in Table 5. Similar to the crude model, no significant risk change was observed in final multivariate model $(\mathrm{HR}=$ $1.17 ; 0.74-1.85, P=.500)$. Other factors significantly associated with poor prognosis in the model were pathologic $\mathrm{N}$ score (2.12 for 1 unit increase, $P<0.001)$ and T score (HR $=1.32$ for 1 unit increase, $P=.006$ ), histology other than adenocarcinoma and squamous cell carcinoma $(\mathrm{HR}=2.63$ relative to adenocarcinoma, $P<001)$, age (1.72 for 1 age category increase, $P<.001)$, percent diffusing capacity for carbon monoxide ( 0.99 for 1 unit increase, $P=.037$ ), and lobectomy with adjacent organ resection $(\mathrm{HR}=2.26$ relative to lobectomy, $P=.004$ ). Therefore, considering propensity to SD and impact of other prognostic factors, SD showed no significant impact on poor survival compared with CD.

Table 6 shows comparisons of operative time, blood loss, and length of hospital stay in all patients and in those who had muscle-sparing thoracotomy. For patients with SD, operative time was shorter (202 minutes for CD vs 169 minutes for $\mathrm{SD}$ ), blood loss was smaller (220 $\mathrm{g}$ for $\mathrm{CD}$ vs $65 \mathrm{~g}$ for
SD) and length of hospital stay was shorter (15 days vs 13 days). When we limited the analysis to patients who had muscle-sparing thoracotomy, eliminating those who had bilobectomy and pneumonectomy, there were also significant differences for each measurement.

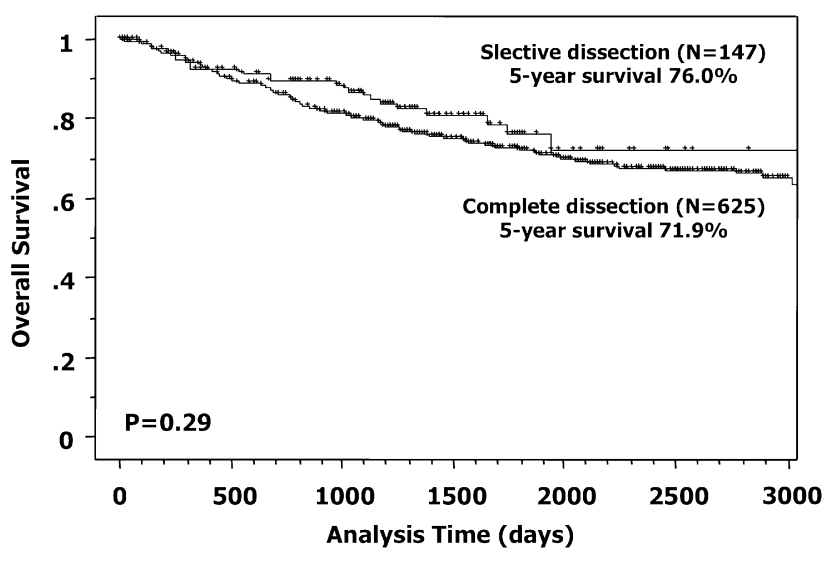

FIGURE 2. Unadjusted overall survival curves of patients stratified by the type of mediastinal dissection (crude). 
TABLE 4. The 5-year survival probabilities stratified by PS quartile

\begin{tabular}{lcccc}
\hline & CD & & SD & \\
\cline { 2 - 2 } & $\begin{array}{c}\text { 5-year survival } \\
(\mathbf{9 5} \% \mathbf{C I})\end{array}$ & & $\begin{array}{c}\text { 5-year survival } \\
(\mathbf{9 5} \% \mathbf{C I})\end{array}$ & $\boldsymbol{P}$ value \\
\hline Total & $71.9 \%(68.0-75.5)$ & & $76.0 \%(65.3-83.9)$ & .29 \\
Quartile 1 & $52.3 \%(44.0-59.9)$ & & $60.0 \%(12.6-88.2)$ & .83 \\
Quartile 2 & $74.8 \%(66.9-81.1)$ & & $73.8 \%(24.4-93.7)$ & .36 \\
Quartile 3 & $83.9 \%(76.6-89.0)$ & & $81.1 \%(62.5-91.9)$ & .55 \\
Quartile 4 & $78.3 \%(68.8-85.2)$ & & $74.9 \%(60.1-84.9)$ & .56 \\
\hline
\end{tabular}

$P S$, Propensity score; $C D$, complete dissection; $S D$, selective dissection.

\section{DISCUSSION}

To date, a number of retrospective or prospective studies for assessment of mediastinal lymph node dissection (CD or sampling) have been performed. ${ }^{3-15}$ Two prospective RCTs compared CD with sampling, ${ }^{4,9}$ but the results were not consistent and the question whether mediastinal lymphadenectomy improved survival was still unresolved.

Several investigators reported that there were distinct patterns of metastatic lymphatic spread based on location of the primary tumors. Watanabe and colleagues ${ }^{14}$ reported that the metastatic prevalence of patients with $\mathrm{pN} 2$ nodes where no $\mathrm{N} 1$ nodes were involved was $7 \%$ to $11 \%$ from upperlobe tumors to the lower part of the mediastinum. Asamura and colleagues ${ }^{15}$ found that the most common site of metastasis for tumors with $\mathrm{pN} 2$ located in right upper lobe or tumors in the left superior division was the superior mediastinal station, whereas metastases to the subcarinal station were seen in only $12 \%$ to $13 \%$ of cases. Indeed, they proposed that subcarinal lymphadenectomy is not always necessary for tumors located there. ${ }^{15}$ There is a report that suggests that 3 stations $(10,11$, or 12$)$ of $\mathrm{N} 1$ lymph nodes or 1 station of N2 nodes (4 for upper-lobe tumors, 5 for left upper-lobe tumors, and 7 for lower-lobe tumors) are sentinel lymph nodes of lung cancer like in breast cancer. ${ }^{5}$ Based on these reports, we take lobe-specific lymph node metastases into consideration for omitting lymph node dissection. Besides, patients with unusual lymph node metastases (ie, patients with subcarinal metastases from upper-lobe tumor, or patients with superior mediastinal metastases from lower-lobe tumor) generally had very poor outcome even when these lymph nodes were systematically dissected.
TABLE 5. A final stepwise multivariate analysis model for overall survival

\begin{tabular}{|c|c|c|c|c|}
\hline Factor & HR & $P$ value & $95 \%$ LCI & $95 \%$ UCI \\
\hline $\begin{array}{l}\text { Lymph node } \\
\text { dissection } \\
\text { (selective vs } \\
\text { complete) }\end{array}$ & 1.17 & .500 & 0.71 & 1.79 \\
\hline pN (continuous) & 2.12 & $<.001$ & 1.80 & 2.50 \\
\hline pT (continuous) & 1.32 & .006 & 1.08 & 1.60 \\
\hline \multicolumn{5}{|l|}{ Pathology } \\
\hline Adenocarcinoma & 1.00 & & & \\
\hline $\begin{array}{l}\text { Squamous cell } \\
\text { carcinoma }\end{array}$ & 1.14 & .523 & 0.76 & 1.71 \\
\hline Others & 2.63 & $<.001$ & 1.74 & 3.98 \\
\hline $\begin{array}{l}\text { Age categories (70-- } \\
60-69,40-59 \text {, and } \\
40-)\end{array}$ & 1.72 & $<.001$ & 1.39 & 2.12 \\
\hline $\begin{array}{l}\% \text { DLCO } \\
\text { (continuous) }\end{array}$ & 0.99 & .037 & 0.99 & 1.00 \\
\hline \multicolumn{5}{|l|}{ Operation } \\
\hline Lobectomy & 1.00 & & & \\
\hline $\begin{array}{l}\text { Middle lobe } \\
\text { lobectomy }\end{array}$ & 0.81 & .562 & 0.39 & 1.68 \\
\hline $\begin{array}{l}\text { Bilobectomy/ } \\
\text { pneumonectomy/ } \\
\text { extended } \\
\text { lobectomy }\end{array}$ & 1.19 & .426 & 0.77 & 1.83 \\
\hline $\begin{array}{l}\text { Lobectomy with } \\
\text { adjacent organ } \\
\text { resection }\end{array}$ & 2.26 & .004 & 1.23 & 3.74 \\
\hline $\mathrm{PaCO}_{2}$ (continuous) & 1.00 & .063 & 1.00 & 1.01 \\
\hline
\end{tabular}

For example, Asamura and associates ${ }^{15}$ reported that right lower-lobe tumors with superior mediastinal metastasis carried a particularly poor 5 -year survival of only $4.1 \%$.

From the above-mentioned data, SD has been often performed by Japanese surgeons especially when the patients were of poor risk and had earlier diseases. In addition, prognostic difference between $\mathrm{CD}$ and $\mathrm{SD}$ is expected to be even smaller than that between $\mathrm{CD}$ and sampling. Okada and colleagues $^{5}$ reported that SD did not worsen prognosis of patients with clinicosurgical stage I NSCLC in their retrospective analysis. The 5 -year OS rate was $79.7 \%$ for $\mathrm{CD}$

TABLE 6. Intraoperative parameters

\begin{tabular}{|c|c|c|c|}
\hline & CD & SD & $P$ value \\
\hline All patients (n) & 625 & 147 & \\
\hline Operative time, min (range) & $201.9 \pm 54.7(97-482)$ & $169.3 \pm 52.2(90-441)$ & $<.001 *$ \\
\hline Blood loss, g (median range) & $220(15-1445)$ & $65(10-1630)$ & $<.001 \dagger$ \\
\hline Length of stay, $\mathrm{d}$ (median range) & $15(6-346)$ & $13(8-117)$ & $<.001 \dagger$ \\
\hline Anteroaxillary thoracotomy, vertical muscle-sparing thoracotomy (n) & 410 & 121 & \\
\hline Operative time, $\min$ (range) & $192.1 \pm 48.9(97-405)$ & $163.3 \pm 44.4(90-371)$ & $<.001 *$ \\
\hline Blood loss, g (median range) & $110(15-1170)$ & $65(10-770)$ & $<.001 \dagger$ \\
\hline Length of stay, days (median range) & $15(6-151)$ & $13(8-117)$ & $<.003 \dagger$ \\
\hline
\end{tabular}

Patients who received lobectomy only (except bilobectomy, pneumonectomy or more). *Unpaired $t$ test. $\dagger$ Mann-Whitney $U$ test. 
and $81.9 \%$ for SD $(P=.149)$. The type of lymph node dissection did not affect OS in the multivariate analysis. However, histologically controlled studies have inherent potential biases in nature.

In this study, we used PS to eliminate such biases as much as possible. We found that there was no significant difference in terms of OS between the 2 groups. However, we admit that the number of covariates to calculate PS was limited. It is clear that firm conclusions must await an adequately designed RCT whose results would be the most important evidence for supporting SD. However, this RCT is almost impossible, and therefore the carefully designed analysis presented here is of great importance.

We also showed that patients who had SD also had significantly shorter operative time, less blood loss, and shorter hospital stay than those who had CD, indicating that SD is less invasive than $\mathrm{CD}$. Okada and associates ${ }^{5}$ reported the morbidity rates (dysrhythmia, pneumonia, prolonged air leak, chylothorax, etc) were significantly less for patients with SD (17.3\% for CD vs $10.1 \%$ for SD, $P=.005)$.

In conclusion, SD did not have significantly impact poor survival compared with CD by our analysis applying PS. In addition, it was suggested that SD was associated with less invasiveness. From the practical point of view, it is reasonable to perform SD especially for patients with no apparent lymph node metastases, those with poor pulmonary reserve, or elderly patients.

\section{References}

1. Naruke T, Goya T, Tsuchiya R, Suemasu K. The importance of surgery to nonsmall cell carcinoma of the lung with mediastinal lymph node metastasis. Ann Thorac Surg. 1988;46:603-9.

2. Martini N, Frehinger BJ, Zaman MB, Beattie EJ. Results of resection in non-oat cell lung carcinoma of the lung with mediastinal lymph node metastases. Ann Surg. 1983;198:386-97.

3. Izbicki JR, Thetter O, Habekost M, Karg O, Passlick B, Kubuschok B, et al. Radical systematic lymphadenectomy in non-small cell lung cancer: a prospective controlled randomized clinical trial. Br J Surg. 1994;81:229-35.

4. Izbicki JR, Passlick B, Pantel K, Pichlmeier U, Hosch SB, Karg O, et al. Effectiveness of radical systematic mediastinal lymphadenectomy in patients with resectable non-small cell lung cancer: results of a prospective randomized trial. Ann Surg. 1998;227:138-44.

5. Okada M, Sakamoto T, Yuki T, Mimura T, Miyoshi K, Tsubota N. Selective mediastinal lymphadenectomy for clinico-surgical stage I non-small cell lung cancer. Ann Thorac Surg. 2006;81:1028-32.

6. Lardionois D, Suter H, Hakki H, Rousson V, Betticher D, Ris HB. Morbidity, survival, and site of recurrence after mediastinal lymph-node dissection versus systematic sampling after complete resection for non-small cell lung cancer. Ann Thorac Surg. 2005;80:268-75.

7. Deslauriers J, Gregoire J. Clinical and surgical staging of non-small cell lung cancer. Chest. 2000;117. 96S-103S.

8. Keller SM, Adak S, Wagner H, Johnson DH. Mediastinal lymph node dissection improves survival in patients with stages II and IIIa non-small cell lung cancer. Eastern Cooperative Oncology Group. Ann Thorac Surg. 2000;70: 358-65.

9. Wu YL, Huang ZF, Wang SY, Yang XN, Ou W. A randomized trial of systematic nodal dissection in resectable non-small cell lung cancer. Lung Cancer. 2002;36: 1-6.

10. Massard G, Ducrocq X, Kochetkova EA, Porhanov VA, Riquet M. Sampling or node dissection for intraoperative staging of lung cancer: a multicentric cross-sectional study. Eur J Cardiothorac Surg. 2006;30:164-7.

11. Whitson BA, Groth SS, Maddaus MA. Surgical assessment and intraoperative management of mediastinal lymph nodes in non-small cell lung cancer. Ann Thorac Surg. 2007;84:1059-65.

12. Allen MS, Darling GE, Pechet TT, Mitchell JD, Herndon JE 2nd, Landreneau RJ, et al. Morbidity and mortality of major pulmonary resections in patients with early stage lung cancer: initial results of the randomized, prospective ACOSOG Z0030. Ann Thorac Surg. 2006;81:1013-20.

13. Okada M, Tsubota N, Yoshimura M, Miyamoto Y. Proposal for reasonable mediastinal lymphadenectomy in bronchogenic carcinomas: role of subcarinal nodes in selective dissection. J Thorac Cardiovasc Surg. 1998;116:949-53.

14. Watanabe Y, Shimizu J, Tsubota M, Iwa T. Mediastinal spread of metastatic lymph nodes in bronchogenic carcinoma. Mediastinal nodal metastases in lung cancer. Chest. 1990;97:1059-65.

15. Asamura H, Nakayama H, Kondo H, Tsuchiya R, Naruke T. Lobe-specific extent of systematic lymph node dissection for non-small cell lung carcinomas according to a retrospective study of metastasis and prognosis. J Thorac Cardiovasc Surg. 1999;117:1102-11.

16. Rosenbaum PR, Rubin DB. Reducing bias in observational studies using subclassification on the propensity score. J Am Stat Assoc. 1984;79:516-24.

17. Naruke T, Suemasu K, Ishikawa S. Lymph node mapping and curability at various levels of metastases in resected lung cancer. J Thorac Cardiovasc Surg. 1978;76: $832-9$.

18. Sobin LH, Wittekind CH, eds. UICC: TNM Classification of malignant tumours. 5th ed. New York: John Wiley \& Sons; 1997. p. 91-100.

19. The World Health Organization histological typing of lung tumours. 3rd ed. Geneva: World Health Organization; 1999.

20. Joffe MM, Rosenbaum PR. Propensity scores. Am J Epidemiol. 1999;150:327-33.

21. StataCorp. STATA for windows: version 10. College Station, Tex: StataCorp; 2007. 